\title{
Aims, design and preliminary findings of the Hellenic National Nutrition and Health Survey (HNNHS)
}

\author{
Emmanuella Magriplis ${ }^{1 \dagger}$, Ioannis Dimakopoulos ${ }^{1 \dagger}$, Dimitra Karageorgou', Anastasia-Vasiliki Mitsopoulou', \\ Ioanna Bakogianni ${ }^{1}$, Renata Micha ${ }^{1,3}$, George Michas ${ }^{1,4}$, Triantafyllia Ntouroupi ${ }^{1}$, Sophia-Maria Tsaniklidou', \\ Kostantina Argyri ${ }^{1}$, George Danezis ${ }^{1}$, Constantinos Georgiou ${ }^{1}$, Demosthenes B. Panagiotakos ${ }^{2}$, Antonis Zampelas ${ }^{1 *}$, \\ HNNHS Contributors and HNNHS Advisory Committee
}

\begin{abstract}
Background: The aim of the Hellenic National Nutrition and Health Survey was to assess nutritional intake, health status and various behaviors in a representative sample of the Greek population.

Methods: Data collection took place from 01.09.2013 to 31.05.2015. Random stratified sampling was performed by (a) geographical density criteria of Greece (7 regions), (b) age group of the reference population $(<19,20-64$ and $>65$ years) and (c) gender distribution. The final population enrolled included (throughout Greece), 4574 individuals (42.5\% men; $57.5 \%$ women of who $47.2 \%$ were from Athens metropolitan area, $18.5 \%$ from Central Macedonia, and the remaining $34 \%$ almost equally scattered throughout the country ( $p$ for the comparisons with official statistics by region, age group and sex $>0.7$ ). Questionnaires developed were based on extensive review of the literature, following a validation procedure when necessary.
\end{abstract}

Results: Preliminary analyses revealed that 32\% of the adult population were overweight and $15.5 \%$ were obese, with significant gender differences in total and per age group $(p<0.001$, for all). The majority of the adult population reported being active smokers (50.4\%) or regular alcohol consumers (72.4\%); with significant gender differences ( $p<0.001$, for all). Prevalence of hyperlipidemia was $16.7 \%$, cardiovascular disease 13.9\%, hypertension 13.3\%, thyroid disease 13.8\%, and Diabetes Mellitus 3.6\%. Significant gender and age group differences were found in various diseases.

Conclusions: Study's preliminary results provide valuable information about the Hellenic population's health. Findings from this survey could be used to detect disease risk factors for public health prevention policies and programs.

Keywords: Diet, Public health, Nutrition survey/ methods, Cross-sectional study, Greece

\section{Background}

The evaluation of current population's mental and physical health and the identification of the most important modifiable risk factors for disease prevention and treatment is mandatory in assuring a healthy and productive population [1-5].

\footnotetext{
* Correspondence: azampelas@aua.gr

${ }^{\dagger}$ Emmanuella Magriplis and Ioannis Dimakopoulos contributed equally to this work.

${ }^{1}$ Department of Food Science and Human Nutrition, Agricultural University of Athens, lera odos 75, 11855 Athens, Greece

Full list of author information is available at the end of the article
}

During the last few decades, a pharmacological approach for public health promotion was widely used, hence focusing mostly on disease treatment rather than prevention. This approach allowed increased prevalence of various health risk factors, and led to an increase in health care costs, and a decrease in gross production. World data have shown that 8 out of the 20 main causes of morbidity and mortality are due to unhealthy nutrition $[1,4,5]$. Recent findings showed that the three leading factors of global disease burden were high blood pressure, smoking, and high alcohol consumption [4, 5], however when globally assessed their geographical variations on the magnitude of their effect of these risks

(c) The Author(s). 2019 Open Access This article is distributed under the terms of the Creative Commons Attribution 4.0 International License (http://creativecommons.org/licenses/by/4.0/) which permits unrestricted use, distribution, and reproduction in any medium, provided you give appropriate credit to the original author(s) and the source, provide a link to the Creative Commons license, and indicate if changes were made. The Creative Commons Public Domain Dedication waiver (http://creativecommons.org/publicdomain/zero/1.0/) applies to the data made available in this article, unless otherwise stated. 
varied with alcohol being the leading risk factor in Eastern Europe and high blood pressure in central Europe, for example. Additionally, overweight and obesity, physical inactivity and other modifiable risk factors (dietary fats) represent substantial risk factors too, with their risk burden varying on diseases by gender, and dietary fats by age (children, adults, elderly) [4,5]. More specifically, older ages had a higher consumption of fish oils, while younger individuals had a higher trans-fat intake [5].

Therefore, well-designed country specific studies are necessary for the assessment and evaluation of major modifiable risk factors in different geographic regions, which will enable a focused (per region's needs) promotion of public health. Additionally, data should also focus in gender and age specific differences.

Efficiently performed well-designed nationally representative cross-sectional studies have adequately evaluated the population's health and nutrition habits. Examples from such programs include the National Health and Nutrition Examination Survey (NHANES) and the National Diet and Nutrition Survey (NDNS). During the last several decades, findings from NHANES have been used in the United States of America (USA) for status and the development of health policies to safeguard public health, including policies for prevention of lead poisoning and folic acid deficiency through compulsory food fortification [6, 7].

The present Hellenic National Nutrition and Health Survey (HNNHS) is the first national cross-sectional study that takes place in Greece, which encompasses a representative sample of all ages, and following standards established by NHANES (USA) and NDNS (United Kingdom).

The aim of the HNNHS was to assess nutritional intake, health status and various behaviors in the Greek population, which could be used to help promote public health through the design and implementation of related policies and intervention programs. In the present paper, the aims, the design and some preliminary findings of the HNNHS are explained below in detail.

\section{Methods}

Study design

This is a cross-sectional observational survey. Responders' selection was performed with a random stratified design based on the 2011 census data. Stratification was made according to (a) geographical density criteria by Greek region (7 regions), as provided by the Hellenic Statistical Authority, (b) age group of the reference population $(<19,20-65$ and $>65$ years $)$ and (c) gender distribution. A random selection of more than one individual per household was possible but no more than one individual from the same age group could be enrolled in the study. If households had children $<6$ years of age, one (if more were present) was randomly selected to be included in the study, upon consent. The sample required to accurately evaluate measures of effect for common risk factors and prevalence of chronic diseases (a priori estimated to equal to 1.2), at 0.05 level (alpha) was 3634 individuals, to achieve a statistical power equal to $85 \%$. To maintain $85 \%$ power in the estimation of prevalence rates of chronic diseases or morbidities equal to $15 \%$, with 1 standard deviation (SD) of the referent population $(N=11,000,000)$, at 0.05 significance, a sample size of 4658 was needed.

\section{Sample}

Invitations were sent to approximately 6000 individuals (anticipating a $70-75 \%$ response rate) in to achieve the required sample size, based on a feasibility and volunteer basis in all Greek regions, by the study's investigators from 01.09.2013 to 31.05.2015. A total 4574 (42,5\% men and $57.5 \%$ women) finally agreed to participate. The sample was distributed throughout Greece, with $47.2 \%$ of it residing in the Athens Metropolitan area, $18.5 \%$ in the region of Central Macedonia, whereas the rest was almost equally scattered throughout the country (Table 1; $\mathrm{p}$ for the comparisons with Official statistics by region, age group and sex $>0.7$ ). Post-hoc assessment, accounting for large population $(N>10,000)$ resulted in a $92 \%$ study power, for an effect size of $1.2(\mathrm{OR}=1.2)$. When the $15 \%$ probability of chronic disease was accounted for, the power was reduced to $84 \%$.

Age standardization was performed using the 2011 Census as the reference population's data to check a-posteriori that the sampled population was representative of the Greek population, as per the aim of the study (calculations are provided in the excel file provided in the Additional files 1 and 2). The population was stratified by 10 years and statistical analyses were performed.

Table 1 Distribution of the sample within Greece

\begin{tabular}{lll}
\hline Prefecture & $\mathrm{N}$ & $\%$ \\
\hline Attica & 2160 & 47.2 \\
Central Macedonia & 844 & 18.5 \\
Epirus & 59 & 1.3 \\
Eastern Macedonia, Thrace & 193 & 4.2 \\
Peloponnese & 144 & 3.1 \\
Western Macedonia & 99 & 2.2 \\
Thessaly & 238 & 5.2 \\
Central Greece & 104 & 2.3 \\
Western Greece & 219 & 4.8 \\
Crete & 262 & 5.7 \\
lonian islands & 51 & 1.1 \\
North Aegean islands & 92 & 2 \\
South Aegean islands & 87 & 1.9 \\
\hline
\end{tabular}


The sampled population was representative for the age groups 0-19, 20-65 and 65+, and, hence were used in the analysis. Furthermore, the prevalence of chronic diseases (surveyed) of the actual Greek population (as per census), through direct standardization, was compared to the prevalence found in the study population. The crude and adjusted odds ratios (OR) calculated by age group in total and by gender did not significantly differ, hence allowing increasing generalizability of the results.

\section{Inclusion - Exclusion criteria}

Total HNNHS sample population included volunteers $\geq 6$ months old that reside in Greece. Exclusion criteria included individuals (i), that did not speak Greek, (ii) women who were at that time breastfeeding or pregnant, (iii) members of the armed forces (including those that are currently undergoing their compulsory military service), (iv) individuals that reside in institutions (e.g. nursing homes, rehabilitation centers, hospice centers, psychiatric institutions, prisons, monasteries), (v) those that were unable to provide informed consent due to any cause (e.g., mental impairment, psychiatric condition, drug abuse, vision or hearing loss) unless a first degree relative was able to assist in the process.

\section{Data collection}

Information was collected via a series of previously validated questionnaires, from the entire population sampled (details given in "Questionnaires in brief" section). All of the questionnaire types used in HNNHS are provided in supplementary tables, along with their validation references in Additional file 1: Tables S1-S3. Additional references are listed for those questionnaires that are not relevant in this study's results.

Clinical examinations were performed on a subsample. More specifically, an initial interview took place at the volunteer's house, with the use of a specially designed computer software (i.e. Computer Assisted Personal Interview (CAPI)), to minimize response biases and misclassification (minimize volunteer burden and maximize reliability of collected data). The list of questionnaires applied can be seen in the Additional file 1: Tables S1 and S2. In summary, the interviewing process included data on (i) demographics, (ii) quality of life (QoL), (iii) medical history (i.e. chronic \& autoimmune diseases, depression, anxiety), (iv) breastfeeding, (v) vitamin and subscribed drug intake, (vi) memory impairment, (vii) eating habits, (viii) alcohol intake, (ix) smoking habits, (x) physical activity, (xi) sleeping habits, (xii) overall patient health, and (xiii) effects of economic crisis. The questionnaires were chosen according to the volunteer's age, as designated by the study's protocol (Additional file 1: Tables S1-S3).

A detailed 24-h dietary recall was obtained during this process. The volunteers were also interviewed for a second 24-h dietary recall via telephone 8-20 days after the first interview, selecting a different day, and non-consecutive, as specified by HNNHS study-protocol. Specific questionnaire structure and validated food atlases for food quantification were used depending on volunteer's age ( $\geq 1.5-4$ years old, $\geq 4-<10$ years old, $\geq 10-<12$ years old and $\geq 12$ years old) in order to maximize response accuracy. More specifically, dietary intake data were collected using two automated multiple-pass 24-h dietary recalls and a Food Propensity Questionnaire (FPQ). To harmonize data collection, we based our food classification and description system on FOOdEx2 developed by EFSA [8], based on volunteers age $(<2$ years old and $\geq 2$ years old). Main differences between the two versions was the food list, (was shorter for the $<2$ year old's), as well as the frequency response section. The latter referred to the frequency of food intake over the last 30 days for volunteers $<2$ years old, or to the past year for those $\geq 2$ years old. Both FPQs were developed based on the Hellenic, European and International guidelines. Overall, the methods of dietary assessment were chosen as per EFSA recommendations for the harmonization of data across countries member states of the European Union [8]. Data on eating patterns and behaviors were also collected (timing of food intake, number of meals, activities performed during food consumption, place of consumption, and others) to account for their effects on individuals weight status as studies support [9-11]. The Nutrition Data System for Research (NDSR) (developed by the University of Minnesota) was used for nutrient analysis.

At the end of the interview, volunteers were provided with a list of questionnaires (hard copy) with specific instructions, to self-complete, based on the volunteer's age and their primary response to disease state during the interviewing process (Additional file 1: Table S2). These were to be fulfilled within a specific time period, to further reduce volunteer burden (time related) and to decrease interviewer and response bias because of the nature of the nature of the questionnaires (sensitive personal information). These questionnaires included (i) qualitative FPQ (asked to be completed by all volunteers, as explained above), (ii) perceived stress scale, (iii) perception of health control, (iii) eating behavior (iv) chronic disease specific information (onset, treatment, medical follow ups, and others), (v) pregnancy and infantile information (i.e., smoking during pregnancy, number of children, weight gain per pregnancy, infant's birth weight/length, breastfeeding (type \& duration), and others), (vi) environmental exposure, (vii) social readjustment factors due to the economic crisis, (viii) asthma related information, and (vi) gastrointestinal disorders (the Greek version of Rome III FGID questionnaires for both children and adults was completed). 
Interview based questionnaires and those to be self-completed were addressed to volunteers $\geq 12$ years old. Questionnaires related to volunteers, less than 12 years old, were addressed to his/her parent or primary guardian.

In the case of volunteers being unable to self-respond (i.e., with inhibiting health complications, adolescents with lack of knowledge in specific questions) a parent/ guardian was asked to assist in the interview. The economic crisis questionnaire was answered only by one adult member per household. Information on primary respondent, or on potential help received during the process was recorded ("interviewee assistant"). A small list of questionnaires where exempt from this procedure (where the main respondent has to be the volunteer himself), due to the nature of the related questions. These included questions on (i) memory impairment, (ii) screen time and alcohol use, ( $\geq 12$ years $-<18$ years), (iv) smoking habits ( $\geq 12$ years $-<18$ years) and (v) patient health questionnaire.

Completed questionnaires were handed to the participants nearest mobile unit or were given to the experienced field investigator (who performed their initial interview), when completed. To achieve a maximum response rate, the study's trained personnel performed kind reminders via phone calls. A total of 3180 volunteers (2682 adults and 498 children and adolescents) completed all questionnaires $(67 \%$ in total; $71 \%$ for adults and $62.6 \%$ for children \& adolescents). Field investigators completed a quality control check-list upon checking the completed questionnaires.

Blood samples were taken from a sub-sample of the population. More specifically, all participants were invited to provide blood samples for biochemical hematological evaluation. Of them, 1197 (26.2\% of total population; $28.7 \%$ of adult population) agreed; no age distribution differences were found between the total population and those who provided blood sample $(p=0.677)$. Each of these individuals visited one of the 5 mobile units where medical and anthropometrics were completed (please see Additional file 1: Table S3). All samples were collected in the morning, between 8:00 and 10:00 am, upon having fasted for at least $10 \mathrm{~h}$. To assure compliance all individuals were asked if they had fasted and when their last meal was.

Experienced field investigators were from various scientific fields (dietitians, physicians, sociologists as well as dietetic and medical students), and received specialized training on the HNNHS fieldwork protocol. These specialists were involved in the development, methodology and application of study questionnaires and protocol procedure attainment was assessed with quality control testing, during field-investigation.

\section{Ethical approval and consent form}

The study was approved by the Ethics Committee of the Department of Food Science and Human Nutrition of the Agricultural University of Athens. It was also approved by Hellenic Data Protection Authority (HDPA). All members of the staff signed confidentiality agreements. Adult volunteers were asked to sign the consent form. For minors $<13$ years of age the parent or primary guardian signed the form and for volunteers between 13 and 18 years of age the consent form was asked to be signed by both (parent/ guardian and volunteer).

\section{Questionnaires in brief}

All questionnaires used in HNNHS, were derived based on a priori knowledge and from components of previously validated questionnaires. For this process. The outcome of interest and previous work performed in the Greek population were also considered.

For demographic characteristics (marital status, education, health insurance, employment, income and changes in employment and/or income during the economic crisis) components from NHANES [12], Behavioral Risk Factor Surveillance System (BRFSS) study [13] and NDNS [14], questionnaires were used.

The Quality of Life (QoL) questionnaire included components of (i) QoL and chronic pain components of the Healthy Days Module developed by the Center for Disease Control (CDC) [15], (ii) questions with regards to self-reported height, weight and oral health, from the Health Survey for England and the Activity Limitations Module (also CDC developed) [16].

Two questionnaires were developed for alcohol consumption; one for minors and the second for adults. For minors ( $\geq 12$ years old and $<18$ years old) the questionnaire was developed based on questions from the Youth Risk Behavior Survey [17], the European School Survey Project and other Drugs [18] and the Global Schoolbased Student Health Survey (GSHS) [19]. For the adult questionnaire data from NHANES study [12], BRFSS [13], Arkansas Cardiovascular Health Examination Survey (ARCHES) [20] and Recommended Alcohol Questions by the National Institute on Alcohol Abuse and Alcoholism (NIAAA) [21] were used. Volunteers were classified as alcohol or non-alcohol consumers, based on their intake over the past 30 days. Frequency of alcohol intake among "consumers" was categorized as daily, weekly or monthly, based on their response on (i) total drinks per month consumed, (ii) drinks per week and/or (iii) drinks per month. For minors, the total number of individuals that reported having consumed an alcoholic drink at some point in life (and not just few sips) was reported.

As in the case of alcohol consumption, smoking habits questionnaire(s) were also based on volunteer's age. In 
particular, for adults questionnaires used were from the NHANES [12] and BRFSS [13] studies; for minors from the Youth Behavior Survey [17], NHANES [12] and the European School Survey Project on Alcohol and other Drugs [18]. Volunteers were grouped into (i) current smokers, if they responded that they had smoked the past month, (ii) ever smokers, if they had smoked at any point in their life, and (iii) non-smokers, if they had never smoked. Frequency of smoking, among current smokers, was also recorded as "daily" or "sometimes". Among minors, the question referred as to whether they had ever tried to smoke (aged up to 19 years).

Weight status was evaluated according to BMI. Body mass Index (BMI) is defined as the weight (in $\mathrm{kg}$ ) over height (in meters squared). Cut-offs used (all in $\mathrm{kg} / \mathrm{m}^{2}$ ) for assessment are widely used and are the following (adults): < 18.5, underweight; 18.5-24.9, normal weight; 25-29.9, overweight; > 30, obese.

Physical activity has a well-known role as a health determinant hence the aim was to assess physical activity levels in all ages. Questionnaires on physical activity were modified based on age groups as per a priori knowledge, including (i) $\geq 2-<12$ years old of the questionnaire was based on questions from the NHANES survey [22] and Preschool-aged Children Physical Activity Questionnaire (Pre-PAQ Home Version) [23] (ii) $\geq 12-<18$ years old, the International Physical Questionnaire - Adolescents (IPAQ-A) [24], (iii) $\geq 18$ years- $<65$ years old the IPAQ short form was used [25] and (iv) for $\geq 65$ years of age a modified version of the IPAQ has been suggested [26]. Preliminary results reported in this study include level of physical activity as perceived by the adult volunteers (sedentary, low, moderate and active) or by the primary care giver if the volunteer was $<12$ years old.

Information about medical history for disease prevalence among the Greek population, related medical treatment and insurance coverage were collected. The synthesis of this questionnaire was based on the National Health Survey, NHANES [12], ARCHES [20], and the Million Women Study [27]. The definition of clinical investigated outcomes was based on the International Classification of Diseases (ICD)-10th version, recorded by experienced study investigators. Diabetes was defined as fasting blood glucose $>125 \mathrm{mg} / \mathrm{dl}$ or if on diabetic medication; dyslipidemia if total triglycerides $>150 \mathrm{mg} / \mathrm{dl}$ and/or total cholesterol $>200 \mathrm{mg} / \mathrm{dl}$ or on lipid-lowering medication; hypertension as average blood pressure greater or equal to $140 / 90 \mathrm{mmHg}$, or on antihypertensive treatment.

Further details on specific disease states (hypertension, dyslipidemia, diabetes) with specific questionnaires [20], were collected once the volunteer declared as having such a condition. In particular, data on prevalence of Chronic Obstructive Pulmonary Disease (COPD) was obtained using the COPD Population Screener [28] and Asthma using the questionnaire from the Hellenic Thoracic Society (for adults), and the Greek version of the questionnaire International Study of Asthma and Allergies in Childhood (ISAAC) [29] (minors 6-18 years old). Following a literature review the Rose Questionnaire for Angina [30] and the Edinburgh Claudication Questionnaire were used in HNNHS [31].

Additional the types of questionnaires used in the study can be viewed in the Additional files 1 and 2 and they included information on breastfeeding, drug and supplement use, memory impairment ( $\geq 45$ years old), eating habits and behavior (as previously reiterated), sleeping habits, data on depression, stress (acute and chronic) \& health locus of control, gestational \& childbirth related questions, environmental exposure, functional gastrointestinal disorders, vitamin D intake status \& sun exposure, and economic crisis, to acquire adequate and substantial information on the population's exposures and risks. Details for each of these questionnaires will be provided upon analysis.

\section{Clinical/ physical evaluation and biochemical variables}

HNNHS also included physical examination (temperature, spirometry, blood pressure, etc.), anthropometry (weight, height, waist and hip circumference, body composition, and grip strength), and several blood tests (glucose, HbA1c (diabetics), insulin, total lipid profile, thyroid hormones, thyroglobulin, PTH, complete blood count, folic acid, iron, ferritin, $\mathrm{B}_{12}, 25 \mathrm{OH}$-vitamin $\mathrm{D}$, creatine, urea, albumin, total protein, ALT, AST, bilirubin, uric acid, calcium, magnesium, manganese, selenium, hs-CRP, cortisol, and heavy metals, namely $\mathrm{As}, \mathrm{Cd}, \mathrm{Co}, \mathrm{Hg}, \mathrm{Mo}, \mathrm{Pb}, \mathrm{Pt}, \mathrm{Sb}$, W, Zn, Ce, La, Th, U) in a subsample of the population, to examine correlations with various health indices in later analyses (Additional file 1: Table S3).

\section{Statistics}

Prior to analysis, data were cross checked for missing values and outliers. Missing information was corrected if the information was derived from other questionnaires and/or measurements (non-reported values of weight and height were completed if the individual was measured at the CAPI). Also, individuals responding as non-diseased but reported taking a disease related medication, were classified as with disease outcome. Baseline socio-demographic are presented as frequencies and percentage $(\mathrm{N}, \%)$ per gender. Variables of interest are presented in total and per gender and age-group (i.e., population's weight status, smoking, alcohol, physical activity, prevalence of chronic disease), while physical activity is presented by specific age groups (as per questionnaires). Chi-square test was used to assess gender differences by age group for weight status, smoking and 
alcohol intake, and for total prevalence of chronic disease by gender. Tukey's paired means test was used to detect differences between age groups (for each chronic diseases). All reported $p$-values were based on two-sided hypothesis tests, with significance level at $5 \%$. The statistical models were computed using STATA 12.0 (STATA corp. Texas).

\section{Results}

\section{Demographic data}

The sample was distributed in all different regions of Greece (Table 1). 47.2\% was in the region of Attica, 18.5\% Central Macedonia, and the rest of the sample being scattered through various regions of Greece $(1.3 \%$ Epirus, 4.2\% Eastern Macedonia and Thrace, 3.1\% Peloponnese, 2.2\% Western Macedonia, 5.2\% Thessaly, 2.3\% Central Greece, 4.8\% Western Greece, 5.7\% Crete, 1.1\% Ionian islands, 2\% North Aegean and 1.9\% South Aegean).

The total number of participants is 4574 volunteers of which 1943 were males and 2629 females. Table 2 shows distribution per gender, age and socioeconomic parameters. Age distribution was representative of the 2011 Census, with $19 \%(N=869)$ of the sampled population being $0-19$ years old, 67\% $(N=3064), 20-64$ years old, and $14 \%(N=639)$ were $\geq 65$ years old. Marital status was as follows: $40.6 \%$ of the population was unmarried (43.3\% males and 38.5\% females), $48.4 \%$ married (51.4\% males and $46.4 \%$ females) and $0.1 \%$ having a cohabitation agreement $6.2 \%$ were widowers $(2.2 \%$ males and $9.2 \%$ females), $3.8 \%$ divorced and $0.7 \%$ separated.

Educational level greatly varied with approximately $32 \%$ having a University degree or greater, $7.1 \%$ had completed secondary education. Approximately $17 \%$ of the population had limited to low education, $27.1 \%$ completed lyceum (12 years of schooling), $5 \%$ technical secondary school and $8.3 \%$ private post-lyceum college. A large percentage of the population $(78.3 \% ; 77.8 \%$ males and $78.8 \%$ females) reported having public health insurance whereas only $4.3 \%$ had private insurance and $8.9 \%$ both types. A total of $8 \%$ males and $6.2 \%$ females were not insured (Table 2).

In terms of net monthly income (Table 2$), 13,5 \%$ had low income $(<€ 300-850), 11.4 \%$ had $€ 851-1050$, approximately $18 \%$ had moderate high income $(€ 1051-$ $1500), 10.6 \%$ had $€ 1501-1900,9.1 \%$ had $€ 1901-2400$, and $10.7 \%$ had high income (€2401-3800 and > €3801).

\section{Weight status and behavioral data}

Sample's self-reported weight status in total by age group ( $>20$ years old) and gender based on Body Mass Index (BMI) can be found in Table 3. A total prevalence of $47.5 \%$ of the adult population was overweight (32\%) and obese (15.5\%), with the prevalence increasing with age in both genders. A significant body weight status difference was found in each age group, with males having a higher prevalence of overweight compared to females $(p<0.001)$ in all age groups.

Frequency of alcohol consumption among adults was $72.4 \%$ (Table 4 ), with approximately $7 \%$ reporting daily consumption, $33 \%$ weekly and $60 \%$ on a monthly basis. A significant greater percentage of males reported of being alcohol consumers than females (81.1\% compared to $67 \%$, respectively; $p<0.001$ ) and being more frequent alcohol consumers as well $(p<0.001)$. Among minors $(12$ to 19 years of age, inclusive), 111 out of 340 individuals (32.6\%) reported as having consumed an alcoholic drink at some point before, and not only a few sips (Table 4). No significant differences were found between genders among minors in alcohol consumption $(p=0.121)$.

Smoking frequency in the total population among adults and minors, per gender, is being shown in Table 5 . Approximately $34 \%$ of the population were current smokers, whereas $50.9 \%$ reported on having smoked at some point in their life. Significant gender differences were found in both cases with a higher proportion of males reporting to have smoked (59\% compared to $44 \%$ ) or of being current smokers (38.3\% compared to 30.8; $p<0.001$ for all). Among current smokers $87.3 \%$ reported to smoke daily with a borderline difference found between genders $(p=0.046)$. A total of $22 \%$ of minors (up to 19 years of age, inclusive) reported of having tried to smoke at some point. No significant gender differences were found ( $p=0.229)$.

Preliminary results of physical activity level were self-reported as sedentary, low activity, moderately and very active (Table 6). The highest proportion of the population being very active was in young children (2-12 years old, 68.6\%) and among adolescents (48.5\%). Twenty - $5 \%$ $(25 \%)$ of adults aged $18-65$ and $>65$ years old reported being very active whereas $20 \%$ of the elderly $(>65)$ reported of having a completely sedentary lifestyle.

\section{Prevalence of chronic disease}

In Table 7, the prevalence of various chronic diseases is presented in total and per age group (20-39, 40-64, and $65+)$ in adults. In each category, gender specific rates can also be viewed. The highest prevalence (16.7\%) was reported for hyperlipidemia (increased cholesterol or triglycerides), with prevalence increasing in both genders with age (Tukey's test $p<0.001$ between groups). The same pattern was found for hypertension with the prevalence mounting to $56 \%$ (51.2\% in males, $61 \%$ in females; $p<0.05)$ in the elderly compared to $1.7 \%$ in adults aged $20-39$ and $17.3 \%$ in the $40-65$ age group (Tukey's test not significant). Accordingly, age patterns were seen in all CVD (CHD, angina, MI, heart failure, arrhythmia and stroke), with significant age group differences found only 
Table 2 Volunteer baseline socio-demographic characteristics by gender

\begin{tabular}{|c|c|c|c|c|}
\hline & \multicolumn{2}{|l|}{ Males } & \multicolumn{2}{|c|}{ Females } \\
\hline & $\mathrm{N}$ & $\%$ & $\mathrm{~N}$ & $\%$ \\
\hline & 1943 & 42.5 & 2629 & 57.5 \\
\hline \multicolumn{5}{|l|}{ Age } \\
\hline $0-19$ & 426 & 21.9 & 443 & 16.9 \\
\hline $20-64^{\mathrm{a}}$ & 1259 & 64.8 & 1805 & 68.7 \\
\hline $20-39$ & 797 & 41.0 & 1040 & 39.6 \\
\hline $40-65$ & 462 & 23.8 & 765 & 29.1 \\
\hline $65+$ & 258 & 13.3 & 381 & 14.5 \\
\hline \multicolumn{5}{|l|}{ Marital status } \\
\hline Unmarried & 841 & 43.3 & 1012 & 38.5 \\
\hline Married & 998 & 51.4 & 1217 & 46.3 \\
\hline Cohabitation agreement & 2 & 0.1 & 2 & 0.1 \\
\hline Widower & 43 & 2.2 & 241 & 9.2 \\
\hline Divorced & 47 & 2.4 & 127 & 4.8 \\
\hline Separated & 10 & 0.5 & 23 & 0.9 \\
\hline Don't know & - & - & 1 & 0 \\
\hline Refused & - & - & 4 & 0.2 \\
\hline \multicolumn{5}{|l|}{ Educational level } \\
\hline No or little education & 25 & 1.6 & 90 & 4 \\
\hline Primary school & 128 & 8.2 & 224 & 9.9 \\
\hline Gymnasium & 81 & 5.2 & 99 & 4.4 \\
\hline Lyceum & 418 & 26.7 & 621 & 27.3 \\
\hline Technical school & 133 & 8.5 & 57 & 2.5 \\
\hline Private college (Post Lyceum) & 114 & 7.3 & 204 & 9 \\
\hline University degree (AEI) & 336 & 21.5 & 517 & 22.7 \\
\hline University degree (TEI) & 144 & 9.2 & 219 & 9.6 \\
\hline Master's degree & 109 & 7 & 188 & 8.3 \\
\hline $\mathrm{PhD}$ & 31 & 2 & 22 & 1 \\
\hline Refused & 4 & 0.3 & 3 & 0.1 \\
\hline \multicolumn{5}{|l|}{ Net monthly income $(€)$} \\
\hline$\leq 300$ & 76 & 3.9 & 106 & 4 \\
\hline $301-650$ & 148 & 7.6 & 285 & 10.8 \\
\hline $651-850$ & 171 & 8.8 & 264 & 10 \\
\hline $851-1050$ & 237 & 12.2 & 283 & 10.8 \\
\hline $1051-1250$ & 172 & 8.9 & 236 & 9 \\
\hline $1251-1500$ & 178 & 9.2 & 237 & 9 \\
\hline 1501-1900 & 222 & 11.4 & 264 & 10 \\
\hline $1901-2400$ & 183 & 9.4 & 231 & 8.8 \\
\hline 2401-3800 & 177 & 9.1 & 202 & 7.7 \\
\hline$>3801$ & 51 & 2.6 & 59 & 2.2 \\
\hline Don't know & 122 & 6.3 & 214 & 8.1 \\
\hline Refused & 204 & 10.5 & 246 & 9.4 \\
\hline
\end{tabular}

Table 2 Volunteer baseline socio-demographic characteristics by gender (Continued)

\begin{tabular}{|c|c|c|c|c|}
\hline & \multicolumn{2}{|l|}{ Males } & \multicolumn{2}{|c|}{ Females } \\
\hline & $\overline{\mathrm{N}}$ & $\%$ & $\overline{\mathrm{N}}$ & $\%$ \\
\hline & 1943 & 42.5 & 2629 & 57.5 \\
\hline \multicolumn{5}{|l|}{ Health insurance } \\
\hline Uninsured & 156 & 8 & 162 & 6.2 \\
\hline Insured, private & 91 & 4.7 & 105 & 4 \\
\hline Insured, public & 1511 & 77.8 & 2071 & 78.8 \\
\hline Insured, both private and public & 157 & 8.1 & 252 & 9.6 \\
\hline Don't know & 10 & 0.5 & 20 & 0.8 \\
\hline Refused & 4 & 0.2 & 3 & 0.1 \\
\hline
\end{tabular}

The sampled population (N\%) in the age group 20-64, was further categorized to 20-39 years and $40-65$ to cross-reference with further analysis performed in these sub-categories

in heart failure (Tukey's test $p=0.014$ for $65+$ compared to 20-39 years). Diabetes prevalence and osteoporosis was also considerably higher in the older age group $(16,8 \%)$ compared to $3.8 \%$ in total population and $16.2 \%$ compared to $5.4 \%$, respectively. Only osteoporosis was significantly different between age groups $(p<0.001$ for 65+ and 20-39 and 40-64). The prevalence of thyroid disease was high in all age groups, especially in females and significantly different between the $65+$ and $20-$ 39-year-old age groups (Tukey's test $p=0.026$ ). A significant difference was also found in cancer prevalence between the older and younger adult age groups (Tukey's test, $p=0.033$ ).

\section{Gender differences and chronic disease}

Significant gender differences were found in hyperlipidemia, arrhythmia, cancer, thyroid disease, osteoporosis, arthritis/rheumatoid arthritis, irritable bowel syndrome, depression, and chronic stress, with females having a significantly higher proportion in each one of them. Prevalence of asthma and cancer was also higher in females, more specifically in the $40-64$ age group ( $4.8 \%$ vs. $1.7 \%$; $p<0.05$ and $3.7 \%$ vs. $0.6 \% ; p<0.01$, respectively). Gender difference was also found in CHD with males having a higher prevalence in the total adult sample and in the older group ( $p<0.001$, for all). The prevalence of MI did not differ in the total sample but was significantly higher in males over 65 years old than females in the same age group $(9.1 \%$ vs. $1.9 \% ; p<0.001)$. Diabetes mellitus was significantly higher in males aged $40-64$ years old than females of the same age group $(5.9 \%$ vs. $2.7 \%$; $p<0.01)$.

\section{Discussion}

The HNNHS was set up in 2013 with the aim to provide comprehensive, nutrition and health information, on a representative sample of the Greek population. Preliminary results of the HNNHS study showed an elevated 
Table 3 Population's weight status in total by age group and gender based on Body Mass Index (BMI) categorization

\begin{tabular}{|c|c|c|c|c|c|c|c|c|}
\hline \multirow{4}{*}{$\begin{array}{l}\text { Weight status } \\
\text { categorization }\end{array}$} & \multirow{3}{*}{\multicolumn{2}{|c|}{ 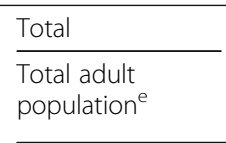 }} & \multicolumn{6}{|c|}{ By age group and gender } \\
\hline & & & \multicolumn{2}{|l|}{$20-39^{a}$} & \multicolumn{2}{|l|}{$40-64^{b}$} & \multicolumn{2}{|l|}{$65+^{c}$} \\
\hline & & & \multicolumn{2}{|l|}{ N (\%) } & \multicolumn{2}{|l|}{$N(\%)$} & \multicolumn{2}{|l|}{ N (\%) } \\
\hline & $\mathrm{N}$ & $\%$ & M & $\mathrm{F}$ & $\mathrm{M}$ & $\mathrm{F}$ & $\mathrm{M}$ & $\mathrm{F}$ \\
\hline Underweight & 175 & 4.7 & $12(1.5)$ & $88(8.5)$ & $5(1.1)$ & $25(3.3)$ & $8(3.1)$ & $37(9.8)$ \\
\hline Normal weight & 1772 & 47.9 & $420(52.7)$ & $722(69.5)$ & 139(30.2) & $335(43.8)$ & $60(23.3)$ & $94(24.8)$ \\
\hline Overweight & 1183 & 32.0 & $285(35.8)$ & $160(15.4)$ & $212(46.0)$ & $244(31.9)$ & $127(49.2)$ & $154(40.6)$ \\
\hline Obese total & 572 & 15.5 & $80(10.0)$ & $69(6.6)$ & 105 & $161(21.1)$ & 63 (24.4) & $94(24.8)$ \\
\hline
\end{tabular}

$N$ (\%) Frequency (percentage), $M$ males, $F$ Females

By gender: \% of males or females in question compared to total number of males or females, respectively

${ }^{a}$ Chi square test for difference in weight status between genders in $20-39$-year-old group $(p<0.001)$

${ }^{\mathrm{b}} \mathrm{Chi}$ square test for difference in weight status between genders in 40-65-year-old group $(p<0.001)$

${ }^{c} \mathrm{Chi}$ square test for difference in weight status between genders in $65+$ year-old group $(p<0.006)$

${ }^{\mathrm{d}}$ Based on BMI $\left(\mathrm{kg} / \mathrm{m}^{2}\right)$ categorization: $<18.5=$ underweight; $20-25=$ normal weight; $>25-30=$ overweight; $>30=$ obese

eStudy population $\geq 20$ years of age; Chi square test for difference in weight status between age groups in total $(p<.001)$ and per gender $(p<.001)$

prevalence of overweight and obesity in adults as well as dyslipidemia and hypertension. Among the adult population prevalence of overweight \& obesity was almost $47 \%$, significantly varying by gender, $17 \%$ of the total population had dyslipidemia, 13\% hypertension and about $4 \%$ had diabetes and $14 \%$ were affected by a form of thyroidism. All outcomes significantly increased with age with prevalence of dyslipidemia and hypertension reaching 45 and $57 \%$ in the elderly, respectively. Furthermore, the prevalence of osteoporosis in Greek women over 65 year of age was $25.8 \%$, a disease that is highly preventable.

In more detail, prevalence of overweight and obesity as well as chronic diseases increased with age with males having overall a higher weight status than females. This is in accordance with data from NHANES showing increased levels of obesity in adults, by sex, age and ethnicity. Hyperlipidemia prevalence in 2011 in Greece was $15 \%$ [32], and results from the ATTICA study reported that 1 in 2 adults $(45 \pm 15)$ years old was dyslipidemic [33].This is in accordance with current results from HNNHS $(44,8 \%$ in total; $39.9 \%$ in males and $48.3 \%$ in females). High levels of hypertension and hyperlipidemia were also found in other studies [34, 35] and policies targeting the reduction of these public health outcomes are warranted as were developed by other countries upon findings [34, 35]. Participation rate was higher in females than males, as has been reported in most European countries [36].

Table 4 Frequency of alcohol consumption habits in minors and adults in total and by gender

\begin{tabular}{|c|c|c|c|c|c|c|c|}
\hline \multirow[t]{3}{*}{ Adults (20+ years) } & \multicolumn{7}{|c|}{ Alcohol consumption* } \\
\hline & \multicolumn{2}{|l|}{ Total } & \multicolumn{2}{|l|}{ Males } & \multicolumn{2}{|c|}{ Females } & \multirow[t]{2}{*}{ Level of significance $^{a}$} \\
\hline & $\mathrm{N}$ & $\%$ & $\mathrm{~N}$ & $\%$ & $\mathrm{~N}$ & $\%$ & \\
\hline \multicolumn{8}{|l|}{ The past 30 days* } \\
\hline No & 998 & 26.9 & 285 & 18.8 & 713 & 32.8 & \multirow[t]{2}{*}{$p<0.001$} \\
\hline Yes & 2685 & 72.4 & 1229 & 81.1 & 1454 & 67.0 & \\
\hline \multicolumn{8}{|l|}{ Frequency } \\
\hline Everyday & 183 & 6.8 & 128 & 10.4 & 55 & 3.8 & \multirow[t]{3}{*}{$p<0.001$} \\
\hline Weekly & 874 & 32.6 & 456 & 37.1 & 418 & 28.8 & \\
\hline Monthly & 1628 & 60.6 & 645 & 52.5 & 981 & 67.5 & \\
\hline \multicolumn{8}{|c|}{ Minors (12-19 years) ** } \\
\hline \multicolumn{8}{|l|}{ Ever consumed } \\
\hline No & 229 & 67.4 & 142 & 89.3 & 153 & 84.5 & \multirow[t]{4}{*}{$p=0.121$} \\
\hline Yes & 111 & 32.6 & 17 & 10.7 & 28 & 15.5 & \\
\hline Don't know & 1 & 0.5 & & & & & \\
\hline Refused & - & - & & & & & \\
\hline
\end{tabular}


Table 5 Frequency of smoking habits in total population among adults and minors by gender

\begin{tabular}{|c|c|c|c|c|c|c|c|}
\hline \multirow[t]{3}{*}{ Adults (20+ years) } & \multicolumn{7}{|c|}{ Smoking** } \\
\hline & \multicolumn{2}{|l|}{ Total } & \multicolumn{2}{|c|}{ Males } & \multicolumn{2}{|c|}{ Females } & \multirow[t]{2}{*}{ Level of significance $^{b}$} \\
\hline & $\bar{N}$ & $\%$ & $\bar{N}$ & $\%$ & $\bar{N}$ & $\%$ & \\
\hline \multicolumn{8}{|l|}{ Ever smoked } \\
\hline No & 1935 & 52.4 & 620 & 41.0 & 1215 & 56.0 & \multirow[t]{2}{*}{$p<0.001$} \\
\hline Yes & 1878 & 50.9 & 893 & 59.0 & 955 & 44.0 & \\
\hline \multicolumn{8}{|l|}{ The past 30 days* } \\
\hline No & 2433 & 65.7 & 934 & 61.5 & 1497 & 68.5 & \multirow[t]{2}{*}{$p<0.001$} \\
\hline Yes & 1252 & 33.8 & 580 & 38.2 & 672 & 30.8 & \\
\hline \multicolumn{8}{|l|}{ Frequency } \\
\hline Every day ${ }^{\mathrm{a}}$ & 1093 & 87.3 & 519 & 89.5 & 574 & 85.4 & \multirow[t]{4}{*}{$P=0.046$} \\
\hline Some days ${ }^{a}$ & 158 & 12.6 & 60 & 10.3 & 98 & 14.6 & \\
\hline Don't know & 1 & 0.1 & & & & & \\
\hline Refused & - & - & & & & & \\
\hline \multicolumn{8}{|l|}{ Minors (10-19 years) } \\
\hline \multicolumn{8}{|l|}{ Ever smoked } \\
\hline No & 100 & 76.3 & 33 & 70.2 & 67 & 79.8 & \multirow[t]{4}{*}{$p=0.229$} \\
\hline Yes & 29 & 22.1 & 12 & 25.5 & 17 & 20.2 & \\
\hline Don't know & 1 & 0.8 & & & & & \\
\hline Refused & 1 & 0.8 & & & & & \\
\hline
\end{tabular}

*For adults (> 19 years of age: 3705 in total): ever smoking; for minors specified if they even tried it (then response yes)

${ }^{a}$ For adults smoking the past 30 days (frequency $(\%)$ of smoking for smokers $N=1252$ )

${ }^{\mathrm{b}}$ Tested via chi square test for gender differences in adult population $\left(20\right.$ years + ) and in minors (up to 19 years); ${ }^{*} p<0.05$; ${ }^{* *} p<0.01 ;{ }^{* * *} p<0.001$;

The proportion of alcohol consumption and current smoking status was high, although the latter, prevalence of smoking, was lower compared to previous findings in the Hellenic population [37]. An alarming proportion of minors had tried alcohol or had smoked at some point. Smoking is a known risk factor for many chronic diseases, including cardiovascular disease, many forms of cancer, asthma and COPD. Alcohol, although has been found to have protective effects on CVD, when consumed in moderation [38], it is forbidden in minors.

Regarding arterial hypertension, the present study's preliminary results are comparable with other studies where hypertension was self-reported ( $13.1 \%$ vs. $13.3 \%$, respectively, $n=5003$ ) [39]. As hypertension is a common risk factor of cardiovascular disease, data on level of awareness is warranted. Efstratopoulos et al., found an awareness level of $60.2 \%$ among Greek hypertensive individuals [40], therefore, further investigation is warranted. The prevalence of hypertension in the NHANES study, for those $\geq 20$ years old was also close to the EPIC and HYPERTENSHELL studies (33.5\%) [41]. A 4\% prevalence of diabetes mellitus was found in this study, reaching $6.3 \%$ for adults over 30 years of age, compared to $7-11 \%$ prevalence reported in Greece among adults [33, 42, 43]. HNNHS included information on thyroid and renal function, for which there are no data available in the Greek population. Respective prevalence levels of 13.7 and $0.6 \%$ of those $\geq 20$ years old were reported. The increased prevalence in all types of thyroid

Table 6 Physical activity levels among different age groups based on self-reported data

\begin{tabular}{|c|c|c|c|c|c|c|c|c|}
\hline \multirow[t]{2}{*}{ Physical activity* } & \multicolumn{2}{|c|}{$\geq 2-<12$ years } & \multicolumn{2}{|c|}{$\geq 12-<18$ years } & \multicolumn{2}{|c|}{$\geq 18-<65$ years } & \multicolumn{2}{|c|}{$\geq 65$ years old } \\
\hline & $\mathrm{N}$ & $\%$ & $\mathrm{~N}$ & $\%$ & $\mathrm{~N}$ & $\%$ & $\mathrm{~N}$ & $\%$ \\
\hline Sedentary way of life & - & - & - & - & - & - & 128 & 20 \\
\hline Low activity & 15 & 3.2 & 24 & 11.7 & 584 & 18.3 & 117 & 18.3 \\
\hline Moderate active, average & 126 & 26.7 & 74 & 35.9 & 1357 & 42.4 & 205 & 32.1 \\
\hline Very active & 324 & 68.6 & 100 & 48.5 & 812 & 25.4 & 160 & 25 \\
\hline Don't know & - & - & 1 & 0.5 & 2 & 0.1 & 1 & 0.2 \\
\hline Refuse to respond & - & - & - & - & 2 & 0.1 & - & - \\
\hline
\end{tabular}

*Individuals were asked to report their perceived physical activity status or to state their child's if they responded on their behalf 
Table 7 Prevalence of chronic disease in adult population sampled, in total, by gender and by gender and age group

\begin{tabular}{|c|c|c|c|c|c|c|c|c|c|c|}
\hline \multirow[t]{3}{*}{ Presence of disease/condition } & \multicolumn{4}{|c|}{ Total } & \multicolumn{6}{|c|}{ By gender and age group ${ }^{a}$} \\
\hline & \multicolumn{2}{|c|}{ Total sample } & \multicolumn{2}{|l|}{$\begin{array}{l}\text { By Genderb } \\
\text { N (\%) }\end{array}$} & \multicolumn{2}{|c|}{$\begin{array}{l}20-39 \\
N(\%)\end{array}$} & \multicolumn{2}{|l|}{$\begin{array}{l}40-64 \\
N(\%)\end{array}$} & \multicolumn{2}{|l|}{$\begin{array}{l}65+ \\
N(\%) \\
\end{array}$} \\
\hline & $\mathrm{N}$ & $\%$ & M & $\mathrm{F}$ & M & $\mathrm{F}$ & M & $\mathrm{F}$ & $\mathrm{M}$ & $\mathrm{F}$ \\
\hline $\begin{array}{l}\text { Increased cholesterol or } \\
\text { triglycerides }{ }^{c}\end{array}$ & 765 & 16.7 & $297^{* * *}(15.2)$ & $468(17.8)$ & $62^{* *}(7.8)$ & $48(4.6)$ & $127(27.6)$ & $226(29.5)$ & $103 *(39.9)$ & $183(48.3)$ \\
\hline Don't know & 175 & 3.8 & & & & & & & & \\
\hline \multirow[t]{2}{*}{ Hypertension } & 608 & 13.3 & $241(12.4)$ & $367(14.0)$ & $21 *(2.6)$ & $11(1.1)$ & $88(19.1)$ & $124(16.2)$ & $132^{*}(51.2)$ & $231(61.0)$ \\
\hline & 47 & 1.0 & & & & & & & & \\
\hline Coronary Heart Disease & 69 & 1.8 & $53^{* * *}(3.4)$ & $16(0.7)$ & $0(0)$ & $1(0.1)$ & $17(3.7)$ & $1(0.1)$ & $36^{* * *}(14.0)$ & $14(3.7)$ \\
\hline Don't know & 32 & 0.8 & & & & & & & & \\
\hline Angina & 36 & 0.9 & $19(1.2)$ & $17(0.8)$ & $6(0.8)$ & $4(0.4)$ & $6(1.3)$ & $2(0.3)$ & $7(2.7)$ & $10(2.6)$ \\
\hline Don't know & 31 & 0.8 & & & & & & & & \\
\hline $\begin{array}{l}\text { Myocardial Infarction } \\
\text { (Heart attack) }\end{array}$ & 49 & 1.3 & $37(2.4)$ & $12(0.5)$ & 0 & 0 & $16^{* *}(3.3)$ & $5(0.7)$ & $21^{* * *}(8.1)$ & $7(1.9)$ \\
\hline Don't know & 13 & 0.3 & & & & & & & & \\
\hline Heart failure & 42 & 1.1 & $16(1.0)$ & $26(1.1)$ & 0 & $3(0.3)$ & $2(0.4)$ & $8(1.1)$ & $14(5.0)$ & $15(4.0)$ \\
\hline Don't know & 27 & 0.7 & & & & & & & & \\
\hline Arrhythmia & 295 & 7.7 & $91^{* *}(5.8)$ & $204(9.0)$ & $21(2.6)$ & $48(4.6)$ & $25(5.4)$ & $71(9.3)$ & $45(17.4)$ & 78 (20.6) \\
\hline Don't know & 42 & 1.1 & & & & & & & & \\
\hline Stroke & 41 & 1.1 & $18(1.1)$ & $23(1.0)$ & $1(0.1)$ & $2(0.2)$ & $3(0.7)$ & $4(0.5)$ & $14(5.4)$ & $17(4.5)$ \\
\hline Don't know & 11 & 0.3 & & & & & & & & \\
\hline Cancer & 53 & 1.2 & $14^{* *}(0.7)$ & $39(1.5)$ & $3(0.4)$ & $1(0.1)$ & $3 * *(0.6)$ & $28(3.7)$ & $8(3.1)$ & $10(2.6)$ \\
\hline Don't know & 8 & 0.2 & & & & & & & & \\
\hline Diabetes (Type I \& II) & 162 & 3.6 & $73(3.8)$ & $89(3.4)$ & $3(0.4)$ & $4(0.4)$ & $27^{* *}(5.9)$ & $21(2.7)$ & $42(16.3)$ & 64 (16.9) \\
\hline Don't know & 24 & 0.5 & & & & & & & & \\
\hline Thyroid (any type of condition) ${ }^{e}$ & 629 & 13.8 & $93^{* * *}(4.8)$ & $536(20.4)$ & $36^{* * *}(4.5)$ & $160(15.4)$ & $26^{* * *}(5.6)$ & $248(32.4)$ & $24^{* * *}(9.3)$ & $113(29.8)$ \\
\hline Don't know & 102 & 2.2 & & & & & & & & \\
\hline Asthma & 184 & 4.0 & $69(3.6)$ & $115(4.4)$ & $40(5.0)$ & $48(4.6)$ & $8^{*}(1.7)$ & $37(4.8)$ & $6(2.3)$ & $20(5.3)$ \\
\hline Don't know & 16 & 0.4 & & & & & & & & \\
\hline $\begin{array}{l}\text { Chronic Obstructive Pulmonary } \\
\text { Disease (COPD) }\end{array}$ & 63 & 1.6 & $25(1.6)$ & $38(1.7)$ & $5(0.6)$ & $8(0.8)$ & $9(2.0)$ & $15(2.0)$ & $11(4.3)$ & $15(4.0)$ \\
\hline Don't know & 77 & 0.6 & & & & & & & & \\
\hline Chronic kidney disease & 27 & 0.6 & $13(0.7)$ & $14(0.5)$ & $3(0.4)$ & $1(0.1)$ & $2(0.4)$ & $4(0.5)$ & $8(3.1)$ & $9(2.4)$ \\
\hline Don't know & 3 & 0.1 & & & & & & & & \\
\hline Osteoporosis $^{f}$ & 206 & 5.4 & $13^{* * *}(0.8)$ & $193(8.3)$ & $1(0.1)$ & $3(0.3)$ & $4^{* * *}(0.9)$ & $95(12.3)$ & $8^{* * *}(3.1)$ & $95(25.8)$ \\
\hline Don't know & 79 & 2.1 & & & & & & & & \\
\hline Arthritis/ Rheumatoid disease & 324 & 7.1 & $65^{* * *}(3.3)$ & $259(9.9)$ & $9^{*}(1.1)$ & $23(2.2)$ & $28^{* * *}(6.1)$ & $106(13.9)$ & $28^{* * *}(10.8)$ & $128(33.8)$ \\
\hline Don't know & 83 & 1.8 & & & & & & & & \\
\hline $\begin{array}{l}\text { Crohn's disease or Ulcerative } \\
\text { colitis }\end{array}$ & 16 & 0.4 & $6(0.3)$ & $10(0.4)$ & $2(0.2)$ & $3(0.3)$ & $1(0.2)$ & $6(0.8)$ & $3(1.2)$ & $1(0.3)$ \\
\hline Don't know & 6 & 0.1 & & & & & & & & \\
\hline Irritable Bowel Syndrome (IBS) & 317 & 6.9 & $53^{* * *}(2.7)$ & $264(10.1)$ & $25^{* * *}(3.1)$ & $105(10.1)$ & $18^{* * *}(3.9)$ & $121(15.8)$ & $9^{*}(3.5)$ & $35(9.2)$ \\
\hline
\end{tabular}


Table 7 Prevalence of chronic disease in adult population sampled, in total, by gender and by gender and age group (Continued)

\begin{tabular}{|c|c|c|c|c|c|c|c|c|c|c|}
\hline \multirow[t]{3}{*}{ Presence of disease/condition } & \multicolumn{4}{|c|}{ Total } & \multicolumn{6}{|c|}{ By gender and age group ${ }^{a}$} \\
\hline & \multicolumn{2}{|c|}{ Total sample } & \multicolumn{2}{|l|}{$\begin{array}{l}\text { By Gender } \\
\text { N (\%) }\end{array}$} & \multicolumn{2}{|c|}{$\begin{array}{l}20-39 \\
N(\%)\end{array}$} & \multicolumn{2}{|l|}{$\begin{array}{l}40-64 \\
N(\%)\end{array}$} & \multicolumn{2}{|l|}{$\begin{array}{l}65+ \\
N(\%)\end{array}$} \\
\hline & $\mathrm{N}$ & $\%$ & M & $\mathrm{F}$ & M & $\mathrm{F}$ & M & $\mathrm{F}$ & M & $\mathrm{F}$ \\
\hline Don't know & 46 & 1.0 & & & & & & & & \\
\hline Depression & 180 & 4.2 & $42^{* * *}(2.3)$ & $138(5.6)$ & $15(1.9)$ & $33(3.2)$ & $12^{* * *}(2.6)$ & $62(8.1)$ & $15(5.8)$ & $42(11.1)$ \\
\hline Don't know & 63 & 1.5 & & & & & & & & \\
\hline Chronic Stress & 495 & 11.6 & $128^{* * *}(7.1)$ & $367(14.9)$ & $56^{* * *}(7.0)$ & $143(13.8)$ & $42^{* * *}(9.1)$ & $134(17.5)$ & $25^{* *}(9.7)$ & $78(20.6)$ \\
\hline Don't know & 39 & 0.9 & & & & & & & & \\
\hline
\end{tabular}

By gender: \% of males or females who reported as having the outcome in question compared to total number of males or females, respectively

By age-group: Number of outcomes reported per gender in each age-group (\%)

${ }^{a}$ Tested via chi square test for gender differences by age group

${ }^{b}$ tested via chi square test for gender differences in total sample; ${ }^{*} p<0.05 ;{ }^{* *} p<0.01 ;{ }^{* * *} p<0.001$

${ }^{c} 3.5 \%$ of the sample replied that they do not know for cholesterol; $<1 \%$ for hypertension, coronary heart disease, angina, myocardial infarction ( 0.3$)$, stroke $(0.3)$, heart failure, arrhythmia (1.1\%), diabetes (0.53), $2.2 \%$ for any thyroid disease, asthma (0.35\%), chronic obstructive pulmonary disorder $(0.63 \%)$. Kidney failure ( $0.1 \%), 2.1 \%$ for osteoporosis, $1.8 \%$ for arthritis, $0.1 \%$ for Crohn's disease, $1.0 \%$ for irritable bowel syndrome, $1.5 \%$ for depression, $0.91 \%$ for chronic stress

dPrevalence for type I diabetes: $3 / 4754$

e-19 age group: for thyroid disease: Males (1.6\%) and females (3.4\%); For asthma: Males (3.5\%), Females (2.3\%); For chronic stress: Males $1.55 \%$, females $4.3 \%$

fOut of which 13 osteopenia

conditions (hypothyroidism, hyperthyroidism, Hashimoto thyroiditis), especially among women, underlies the value of HNNHS and stresses the need to further investigate risk factors linked to this outcome, such as iodine and vitamin D status, as well as nutritional intake and search for deficiencies. The prevalence of cardiovascular disease, the leading cause of mortality worldwide, found in the study population was $13.9 \%$, in total. This included $7.7 \%$ of the total sample that reported having arrhythmia, 1.8\% coronary heart disease, $1.3 \%$ myocardial infarction, $0.9 \%$ angina, 1.1 heart failure, and $1.1 \%$ had suffered a stroke.

Furthermore, an increased level of stress-associated disorders including chronic perceived stress (11.6\%), depression (4.2\%), Crohn's disease $(0.4 \%)$ or ulcerative colitis $(0,4 \%)$, and irritable bowel syndrome (6.9\%) were found. These outcomes may be associated with the economic crisis seen in Greece over the past years but can also be linked to various nutritional and behavioral factors, that need to be examined. Interestingly, data with regards to perceived change in household budget show that most volunteers perceived change being more severe in $2012(23.2 \%)$ than 2011 (18.3\%) and 2013 (12.6\%). Details that may have affected these stress-associated disorders, remain to be investigated.

\section{Limitations}

Due to the cross-sectional nature of the study, no causal relationships can be formulated. Also, the data presented and analyzed in this first report are from reported data. However, experienced field investigators checked the data and recorded clinical outcomes based on ICD-10th version codes. Furthermore, sensitive personal questions, were self-completed to decrease reporting bias. All clinical outcome data were further cross-checked with other related questions, ie, medications, in order to accurately code the participants and decrease misclassification. Reporting of data in more depth and comparison with other past small, non-nationally representative surveys in Greece are beyond the scope of this first methodological publication and will be described elsewhere.

\section{Strengths}

Health surveys as HNNHS can reveal target groups in need for prevention strategies according to educational level, employment and marital status, area of residence in a subnational level, and health behavior [40, 44]. HNNHS, is the first national representative study performed in Greece to assess nutrition and health status of the population including all age groups. Questionnaires used were constructed after performing an extensive literature review and based on other validated questionnaires that have been used in other large national studies and in the Greek population. Another strength is the synergistic action of multiple health care specialists in study design, filed work and data analysis. Furthermore, the use of the especially designed computer software, CAPI, increases reliability of collected data, since it reduces response bias, misclassification and volunteer burden. Measurements, clinical assessment and blood tests performed in a subsample of the population will be used to further validate the preliminary results presented here.

\section{Conclusions}

The HNNHS study aims to evaluate the health of the Greek population. The data presented provide a preliminary overview of demographic and lifestyle data of the population. We envision that this study will provide valuable information regarding the health of the Greek population and that it will become a rolling program that will facilitate the development and evaluation of public health policies addressing key risk factors that impact on the health of the Greek population. 


\section{Additional files}

Additional file 1: Table S1. List of questionnaires applied to volunteers according to age during the initial interview. Table S2. List of questionnaires to be self-completed at home, according to age. Table S3. List of exams and questionnaires applied to volunteers, according to age, during their visit to the mobile unit. (DOCX $38 \mathrm{~kb}$ )

Additional file 2: 3 worksheets (All, Males, Females) for age adjusted chronic disease calculations, standardized by Hellenic population distribution (2011 Census). (XLSX 35 kb)

\section{Abbreviations}

ARCHES: Arkansas Cardiovascular Health Examination Survey; BRFSS: Behavioral Risk Factor Surveillance System; CAPI: Computer Assisted Personal Interview; CDC: Centre for Disease Control; CHD: Coronary Heart Disease; COPD: Chronic Obstructive Pulmonary Disease; CVD: Cardiovascular disease; DM: Diabetes Mellitus; EFSA: European Food Safety Authority; EPIC: European Prospective Investigation into Cancer and Nutrition; FGID: Functional Gastrointestinal Disorders; FPQ: Food Propensity Questionnaire; GSHS: Global School-based Student Health Survey; HDPA: Hellenic Data Protection Authority; HNNHS: Hellenic National Nutrition and Health Survey; IPAQ: International Physical Activity Questionnaire; ISAAC: International Study of Asthma and Allergies in Childhood; Ml: Myocardial Infarction; MRC: Medical Research Council; NatCen: NatCen Social Research; NDNS: National Diet and Nutrition Survey; NDSR: Nutrition Data System for Research; NHANES: National Health and Nutrition Examination Survey; NIAAA: National Institute on Alcohol Abuse and Alcoholism; OR: Odds ratio; QoL: Quality of Life; USA: United States of America

\section{Acknowledgments}

The study was co-funded by Greece and the European Union (European Social Fund) under the Operational Program "Human Resources Development 2007-2013".

Contributors:

Evangelia Fappa', Eleni-Maria Theodoraki', Eirini Trichia', Theodora-Eirini Sialvera', Aggeliki Varytimiadi1, Eleni Spyreli', Michalis Chourdakis ${ }^{4}$, Antonis Koutelidakis ${ }^{5}$, George Karlis ${ }^{1}$, Stauroula Zacharia ${ }^{1}$, Anna Papageorgiou'. Advisory Committee:

George P. Chrousos ${ }^{3}$, Georgios Dedoussis ${ }^{2}$, George Dimitriadis ${ }^{6}$, loannis Manios $^{2}$, Eleftheria Roma ${ }^{3}$.

Field workers:

Ioanna Adami, Aggeliki Anastasiou, Elisavet Anestiadou, Nikolaos Altanis, Georgios Arguropoulos, Euaggelia Arvanitidou, Anastasios Barounis, Alexandra Basdeki, Polychronis Bazakidis, Dimitra Borsa, Vasileia Chatzistergiou, Theodoros Chrysanidis, Konstantinos Daskalou, Chrysaugi Galanaki, Chrysanthi Gerasimatou, Arriana Gkouvi, Lampros Grampsas, Eleni Ioannidi, Vasiliki Kanaki, Eustratios, Karagiannidis, Eirini Kasapidou, Vasiliki Katseni, Georgios Koktsidis, Eirini Konstantakou, Andronikos, Kostakidis, Sotiria Kottara, Eleutheria Kourliti, Maria Kourtidou, Aikaterini Lymperopoulou, Nikoleta, Markoglou, Aikaterini Markou, Anna Mauromanoli, Panagiota Merou, Areti Miha, Marianna Moira, loannis Moschakis, Dimitra Mougopetrou, Konstantina Mouliou, Andromachi Mourtzouhou, Vasiliki Moustakaki, Vissarios Moutsanas, Maria-Aggeliki Mpoulet, Evangelia Nanou, loannis Nikolaidis, Giannos-Aggelos Nikolaou, Sakellarios Panagiotakis, Eirini Panagiotou, Panagiotis Papadopoulos, Vasiliki Papageorgiou, Nikolaos Papaspanos, Olga Papazisi, Euthymia-Iro Pappa, Eufrosyni Patiraki, Konstantinos Petsanis, Maria-Christina Polychronopoulou, Nikolitsa Psylia, Alexandros Sachinidis, Avraam Sarafopoulos, Paraskevi Seferidi, Christos Sifnaios, Dimitra Stauropoulou, Myrto Stavrou, Chrysanthi Tatsi, Nena Theodoridou, Anna Theou, ChristinaYakinthi Tzotziou, Georgios Vergos, Agapi, Vlachou, Anastasia Xatziapostolou, lliana Xatzifragou, Adela Zana.

\section{Funding}

The study was co-funded by Greece and the European Union (European Social Fund) under the Operational Program "Human Resources Development 2007-2013".

\section{Availability of data and materials}

The datasets used and/or analyzed during the current study are available from the corresponding author on reasonable request.

\section{Authors' contributions}

AZ conceptualized, designed and was the Principal Investigator of the study. AZ and RM coordinated the design of the data collection instruments, coordinated and supervised data collection. GM supervised medical data collection. ID, DK, AVM and IB were involved in every step of the study and made substantial contributions to the design and methodology of data collection as well as the acquisition of data and training of field workers. TN coordinated mobile unit data collection. SMT and KA contributed to the mobile unit data collection and analysis. DBP coordinated sample collection methodology. ID drafted the manuscript equally with EM. EM also supervised the design and the preparation of the data base and carried out the statistical analyses and revised the manuscript. GD, CG, EF, EMT, ET, TES, AV ES, MC, AK, GK, SZ and AP contributed to parts of methodology. All the authors approved the final manuscript as submitted. Contributors: EF, ET, TS, $A V, E S, M C, A T, G K, S Z, A P$ contributed to the writing of the protocols and the data collection on the field. All contributors approved the final manuscript as submitted. Advisory Committee: GC, GD, GD, IM and ER acted as external advisory committee. All the Advisory Committee members approved the final manuscript as submitted. All authors read and approved the final manuscript.

\section{Ethics approval and consent to participate}

The study was approved by the Ethics Committee of the Department of Food Science and Human Nutrition of the Agricultural University of Athens. It was also approved by Hellenic Data Protection Authority. All members of staff signed confidentiality agreements and all participants, as well as the parent/ guardian when required, were asked to sign a consent form.

\section{Consent for publication}

Not applicable.

\section{Competing interests}

The authors declare that they have no competing interests. Professor Demosthenes Panagiotakos, co-author of this paper, serves as a Section Editor of the BMRM Journal.

\section{Publisher's Note}

Springer Nature remains neutral with regard to jurisdictional claims in published maps and institutional affiliations.

\section{Author details}

${ }^{1}$ Department of Food Science and Human Nutrition, Agricultural University of Athens, lera odos 75, 11855 Athens, Greece. ²Department of Nutrition and Dietetics, School of Health Science and Education Harokopio University, Athens, Eleftheriou Venizelou 70, 17676 Athens, Greece. ${ }^{3}$ Present Address: Friedman School of Nutrition Science and Policy, Tufts University, Boston, USA. ${ }^{4}$ Present Address: Department of Cardiology, "Elpis" General Hospital of Athens, Athens, Greece.

Received: 16 July 2018 Accepted: 27 December 2018

Published online: 20 February 2019

\section{References}

1. Mozaffarian D, Fahimi S, Singh GM, Micha R, Khatibzadeh S, Engell RE, Lim S, Danaei G, Ezzati M, Powles J. Global sodium consumption and death from cardiovascular causes. N Engl J Med. 2014;371(7):624-34.

2. Wing RR, Bolin P, Brancati FL, Bray GA, Clark JM, Coday M, Crow RS, Curtis JM, Egan CM, Espeland MA, et al. Cardiovascular effects of intensive lifestyle intervention in type 2 diabetes. N Engl J Med. 2013; 369(2):145-54.

3. Sacks FM, Svetkey LP, Vollmer WM, Appel LJ, Bray GA, Harsha D, Obarzanek E, Conlin PR, Miller ER 3rd, Simons-Morton DG, et al. Effects on blood pressure of reduced dietary sodium and the dietary approaches to stop hypertension (DASH) diet. DASH-sodium collaborative research group. N Engl J Med. 2001;344(1):3-10.

4. Lim SS, Vos T, Flaxman AD, Danaei G, Shibuya K, Adair-Rohani H, Amann M, Anderson HR, Andrews KG, Aryee M, et al. A comparative risk assessment of burden of disease and injury attributable to 67 risk factors and risk factor clusters in 21 regions, 1990-2010: a systematic analysis for the global burden of disease study 2010. Lancet. 2012;380(9859):2224-60.

5. Micha R, Khatibzadeh S, Shi P, Fahimi S, Lim S, Andrews KG, Engell RE, Powles J, Ezzati M, Mozaffarian D. Global, regional, and national consumption levels of 
dietary fats and oils in 1990 and 2010: a systematic analysis including 266 country-specific nutrition surveys. BMJ. 2014;g2272:348.

6. Pirkle JL, Brody DJ, Gunter EW, Kramer RA, Paschal DC, Flegal KM, Matte TD. The decline in blood lead levels in the United States. The National Health and nutrition examination surveys (NHANES). Jama. 1994;272(4):284-91.

7. Zavras D, Tsiantou V, Pavi E, Mylona K, Kyriopoulos J. Impact of economic crisis and other demographic and socio-economic factors on self-rated health in Greece. Eur J Pub Health. 2013;23(2):206-10.

8. EU menu declaration [https:/www.efsa.europa.eu/en/data/foodconsumption-data]. Accessed May 2018.

9. Veugelers PJ, Fitzgerald AL. Prevalence of and risk factors for childhood overweight and obesity. CMAJ. 2005;173(6):607-13.

10. Barlow SE, Expert C. Expert committee recommendations regarding the prevention, assessment, and treatment of child and adolescent overweight and obesity: summary report. Pediatrics. 2007;120(Suppl 4):S164-92.

11. Dattilo AM, Birch L, Krebs NF, Lake A, Taveras EM, Saavedra JM. Need for early interventions in the prevention of pediatric overweight: a review and upcoming directions. J Obes. 2012;2012:123023.

12. National Health and Nutrition Examination Survey [http://www.cdc.gov/ nchs/nhanes.htm]. Accessed May 2018.

13. Behavioral Risk Factor Surveillance System Survey Questionnaire [http:// www.cdc.gov/brfss/]. Accessed May 2018.

14. National Diet and Nutrition Survey, Medical Research Council [https://www. gov.uk/government/collections/national-diet-and-nutrition-survey]. Accessed May 2018.

15. Measuring healthy days: Population assessment of health-related quality of life [http://www.cdc.gov/hrqo//hrqol14_measure.htm]. Accessed May 2018.

16. Health Survey for England [http://www.ucl.ac.uk/iehc/research/ epidemiology-public-health/research/hssrg/studies/health-survey-england]. Accessed May 2018.

17. Youth Risk Behavior Survey [www.cdc.gov/yrbs]. Accessed May 2018.

18. The European School Survey Project on Alcohol and other Drugs [http:// www.espad.org]. Accessed May 2018.

19. World Health Organisation. The School-Based Student Health Survey (GSHS) [http://www.who.int/chp/gshs/methodology/en/index.html]. Accessed May 2018.

20. Zohoori N, Pulley L, Jones C, Senner J, Shoob H, Merritt RK. Conducting a statewide health examination survey: the Arkansas cardiovascular health examination survey (ARCHES). Prev Chronic Dis. 2011;8(3):A67.

21. National Institute on Alcohol Abuse and Alcoholism. The Recommended Alcohol Questions [http://www.niaaa.nih.gov/research/guidelines-andresources/recommended-alcohol-questions]. Accessed May 2018.

22. Timmons BW, Naylor PJ, Pfeiffer KA. Physical activity for preschool children-how much and how? Can J Public Health. 2007;98(Suppl 2):S122-34.

23. Dwyer GM, Hardy LL, Peat JK, Baur LA. The validity and reliability of a home environment preschool-age physical activity questionnaire (pre-PAQ). Int J Behav Nutr Phys Act. 2011;8:86.

24. Hagstromer M, Bergman P, De Bourdeaudhuij I, Ortega FB, Ruiz JR, Manios Y, Rey-Lopez JP, Phillipp K, von Berlepsch J, Sjostrom M. Concurrent validity of a modified version of the international physical activity questionnaire (IPAQ-A) in European adolescents: the HELENA study. Int J Obes. 2008; 32(Suppl 5):S42-8.

25. Craig CL, Marshall AL, Sjostrom M, Bauman AE, Booth ML, Ainsworth BE, Pratt M, Ekelund U, Yngve A, Sallis JF, et al. International physical activity questionnaire: 12-country reliability and validity. Med Sci Sports Exerc. 2003; 35(8):1381-95

26. Heesch $\mathrm{KC}$, van Uffelen JG, Hill RL, Brown WJ. What do IPAQ questions mean to older adults? Lessons from cognitive interviews. Int J Behav Nutr Phys Act. 2010;7:35.

27. National Health Survey: The Million Women Study. [http://www millionwomenstudy.org/questionnaires]. Accessed May 2018.

28. Martinez FJ, Raczek AE, Seifer FD, Conoscenti CS, Curtice TG, D'Eletto T, Cote C, Hawkins C, Phillips AL. Group C-PCW: development and initial validation of a self-scored COPD population screener questionnaire (COPD-PS). COPD. 2008:5(2):85-95.

29. Ellwood P, Asher Ml, Beasley R, Clayton TO, Stewart AW, Committee IS. The international study of asthma and allergies in childhood (ISAAC): phase three rationale and methods. Int J Tuberc Lung Dis. 2005;9(1):10-6.

30. Rose G, McCartney P, Reid DD. Self-administration of a questionnaire on chest pain and intermittent claudication. Br J Prev Soc Med. 1977:31(1):42-8.
31. Leng GC, Fowkes FG. The Edinburgh claudication questionnaire: an improved version of the WHO/Rose questionnaire for use in epidemiological surveys. J Clin Epidemiol. 1992;45(10):1101-9.

32. Maniadakis N, Kourlaba G, Fragoulakis V. Self-reported prevalence of atherothrombosis in a general population sample of adults in Greece; a telephone survey. BMC Cardiovasc Disord. 2011;11:16.

33. Panagiotakos DB, Pitsavos C, Chrysohoou C, Skoumas I, Stefanadis C. Prevalence and five-year incidence (2001-2006) of cardiovascular disease risk factors in a Greek sample: the ATTICA study. Hell J Cardiol. 2009;50(5):388-95.

34. Flegal KM, Carroll MD, Kit BK, Ogden CL. Prevalence of obesity and trends in the distribution of body mass index among US adults, 1999-2010. Jama. 2012;307(5):491-7

35. Freid VM, Bernstein AB, Bush MA. Multiple chronic conditions among adults aged 45 and over: trends over the past 10 years. NCHS data brief. 2012:100:1-8.

36. Mindell JS, Giampaoli S, Goesswald A, Kamtsiuris P, Mann C, Mannisto S, Morgan K, Shelton NJ, Verschuren WM, Tolonen H. Sample selection, recruitment and participation rates in health examination surveys in Europe--experience from seven national surveys. BMC Med Res Methodol. 2015;15:78.

37. Panagiotakos DB, Georgousopoulou EN, Pitsavos C, Chrysohoou C, Metaxa V, Georgiopoulos GA, Kalogeropoulou K, Tousoulis D, Stefanadis C. Group AS: ten-year (2002-2012) cardiovascular disease incidence and all-cause mortality, in urban Greek population: the ATTICA study. Int J Cardiol. 2015; 180:178-84

38. Wood AM, Kaptoge S, Butterworth AS, Willeit P, Warnakula S, Bolton T, Paige E, Paul DS, Sweeting M, Burgess S, et al. Risk thresholds for alcohol consumption: combined analysis of individual-participant data for 599912 current drinkers in 83 prospective studies. Lancet. 2018;391(10129):1513-23.

39. Pitsavos C, Milias GA, Panagiotakos DB, Xenaki D, Panagopoulos G, Stefanadis C. Prevalence of self-reported hypertension and its relation to dietary habits, in adults; a nutrition \& health survey in Greece. BMC Public Health. 2006:6:206.

40. Efstratopoulos AD, Voyaki SM, Baltas AA, Vratsistas FA, Kirlas DE, Kontoyannis JT, Sakellariou JG, Triantaphyllou GB, Alokrios GA, Lianas DN, et al. Prevalence, awareness, treatment and control of hypertension in Hellas, Greece: the hypertension study in general practice in Hellas (HYPERTENSHELL) national study. Am J Hypertens. 2006;19(1):53-60.

41. Hypertension [https://www.cdc.gov/nchs/fastats/hypertension.htm]. Accessed May 2018.

42. Liatis S, Dafoulas GE, Kani C, Politi A, Litsa P, Sfikakis PP, Makrilakis K. The prevalence and treatment patterns of diabetes in the Greek population based on real-world data from the nation-wide prescription database. Diabetes Res Clin Pract. 2016:118:162-7.

43. Panagiotakos DB, Pitsavos C, Chrysohoou C, Stefanadis C. The epidemiology of type 2 diabetes mellitus in Greek adults: the ATTICA study. Diabet Med. 2005;22(11):1581-8.

44. Pigeot I, De Henauw S, Foraita R, Jahn I, Ahrens W. Primary prevention from the epidemiology perspective: three examples from the practice. BMC Med Res Methodol. 2010;10:10.

Ready to submit your research? Choose BMC and benefit from:

- fast, convenient online submission

- thorough peer review by experienced researchers in your field

- rapid publication on acceptance

- support for research data, including large and complex data types

- gold Open Access which fosters wider collaboration and increased citations

- maximum visibility for your research: over $100 \mathrm{M}$ website views per year

At $\mathrm{BMC}$, research is always in progress.

Learn more biomedcentral.com/submission 